\title{
What Can A [Feminist] Body Do? Immanent and Emergent Capacities of Bodies at Chinchorro and Wor Barrow
}

\author{
Yvonne O’Dell \& Oliver J.T. Harris
}

\begin{abstract}
What can a body do? To answer Baruch Spinoza's question, we engage with posthumanist feminist concepts of nomadic subjectivity and relations with non-humans. Through an exploration of two 'patches', the Chinchorro Mummies of the Atacama Desert in South America and the burials at Wor Barrow in the Neolithic of southern England, we suggest that these approaches open up a new way of encountering past bodies. What capabilities do bodies, past and present, have? This question is one in which bodies' capacities are revealed as immanent, historically contextual and emergent.
\end{abstract}

\section{Introduction}

Let us begin by thinking about two very different mummified bodies. ${ }^{1}$ The first (Cam-17 T1:C3) was once a human infant, less than six months old, but through a complex process of mummification is now a composition of human and non-human, animal and person. Their extremities are enveloped in the skin of a sea lion, their crown adorned with a wig of adult human hair. Their skull is replaced with skin covered balls of clay. The human body is very deliberately altered. The process of transformation from living human infant to mummified form extended the body's temporality, slowing the vibrant decay of skin and flesh. The human body was given different capacities: it was bound to earth and sea, its infancy complicated by the addition of adult human hair. This transformation of time allows the body to do new things, to engage in new relationships, to enter new places. It lets the body become something else, a new shifting amalgam of materials, people, times, animals, places and potentials. Processes like this repeatedly created new possibilities for bodies on the coast of the Atacama Desert in South America for thousands of years.

Overlapping with this body chronologically, but separated by 6000 miles, we can explore the contrasting treatment of one individual on an island in northwest Europe. Unlike almost every other local contemporary person, this individual was preserved articulated, and intact, for a century or more after his death. In contrast to others, this mummified body gained the capacity to continue to engage with and influence the living in death as a whole, not a fragment. The body of this man, aged between 25 and 35 when he died, perhaps violently, gained new potentials to act in new ways here. It could do things differently.

These two preserved corpses, from different sides of the world, one part of a wide tradition of mummification, the other not, pose a simple question for us here in the present: what can a body do? This question has too often been taken for granted by archaeologists. It sounds so simple, yet it opens a host of critical routes for investigation. It is a question posed to us by the seventeenth-century philosopher Baruch Spinoza, and one that now returns with force, powered by posthumanist feminism. In this paper, we explore how new capacities emerge via the transformations through which these bodies went, and how new understandings await archaeologists when we approach such bodies open to the possibilities of difference that they offer us.

\section{Archaeologies of the body}

Archaeology has engaged critically with issues of the body for almost 30 years (Meskell \& Joyce 2003; Robb \& Harris 2013; Yates 1993). Approaches influenced by

Cambridge Archaeological Journal 32:2, 295-303 @ The Author(s), 2022. Published by Cambridge University Press on behalf of the McDonald Institute for Archaeological Research. This is an Open Access article, distributed under the terms of the Creative Commons Attribution licence (https:// creativecommons.org/licenses/by/4.0/), which permits unrestricted re-use, distribution, and reproduction in any medium, provided the original work is 
phenomenology have explored what it is a body experiences (e.g. Tilley 1994); others have offered detailed readings of body symbolism through examining clothes and grave goods (e.g. Treherne 1995). Joanna Sofaer (2006) has shown us in detail how the physical matter of bodies is shaped by, and shapes, the world it encounters, how bones thicken via repeated actions, how muscle attachments form, how disease marks the body through life. John Robb and Oliver Harris (2013) have explored the multiple 'body worlds' of Europe, from 40,000 BC to the present day, examining how different sets of relationships with animals, places, metaphors, beliefs and machines made different conceptions of the body, and different bodies themselves, central to human life. Archaeologists have explored the embodied nature of our practice in the field (e.g. Edgeworth 2012) and how our work as analysts in laboratories, armed with a range of technologies, allows biological sex to emerge as a material phenomenon (Marshall \& Alberti 2014). While space prevents a broader review of this rich and varied literature, suffice it to say here that archaeological investigations of bodies and embodiment has been a hugely rewarding field over the last 30 years.

What, then, can posthumanist feminism bring to this account (see Cobb \& Crellin, this section; cf. Crellin \& Harris 2021; Crellin et al. 2021; Marshall 2021)? As Christina Fredengren (2013; 2018) has shown, posthumanism speaks directly to our processes of working with and thinking about bodies. Her work specifically examines how osteoarchaeologists study bodies, and how a posthumanist analysis reveals how our analysis remains structured by competing demands of essentialism on the one hand and social constructivism on the other (Fredengren 2018, 137; see also Marshall \& Alberti 2014). Here, though, we want to explore what it is that posthumanist feminism can bring to our accounts of bodies in the past, as well as past bodies that are present today. We build on the powerful ways of thinking about bodies that archaeology already provides, by developing an approach that celebrates a refusal to elevate a particular model of humanity, that undercuts and turns away from dualisms, and that recognizes the inherent flaws with anthropocentrism (Ferrando 2019). We seek to answer a single question: what can a body do (Deleuze 1988, 17)? That question leads us to an encounter with difference, with nomadic thought (Braidotti 2011), and with a reconsideration of bodily capacities to act in the world. Our posthumanism suggests that we see these bodies as always emergent through relations, and not necessarily human. Our feminism demands we recognize the contribution that thinking in this way makes to our present and future, as well as to the past, a point we will return to in our conclusion.

\section{What can a body do?}

Our question, as noted above, comes from the seventeenth-century Dutch philosopher Spinoza. In Part III of his Ethics he stated 'No one has hitherto laid down the limits to the powers of the body' (Spinoza 2009, Part III, Prop. II). In making this claim, that nobody knows what a body can do, Spinoza is not bemoaning the limits of scientific knowledge. Rather, he writes from a position of immanence. Spinoza was radical for his time because he believed in the univocity of being: God and nature are one and the same, and our human bodies are expressions of a single nature. In this way, there is no transcendent, external plan of what the human body (or more than human body) is, or what it can do. Bodies are always immanent. To quote Spinoza again, 'Bodies are distinguished from one another in respect of motion and rest, quickness and slowness, and not in respect of substance' (2009, Part II, Prop. XIII; cf. Deleuze 1988). We cannot separate a body from the process of what the philosopher Gilles Deleuze (2006) would go on to call its becoming. The way that bodies are distinguishable from one another arises in the way that bodies are expressed, contextually, alongside other bodies. Thus, bodies must always be relational-because they are always already emerging in and through relations. These relations neither follow on from bodies, nor pre-exist them, but rather emerge in parallel with them. Moreover, this relational and emergent approach means no hierarchy need be imposed; Spinoza was an early example of a flat ontologist, embracing a singular univocity in comparison to the dualisms of Descartes (Cipolla 2021; Harris 2021, 46-7). Humans are not placed above anything else in his philosophy.

Here the issues raised by feminism cause us to rephrase this question: what can a feminist body do? The form of feminism we draw on here can be found in the work of posthumanist thinkers like Rosi Braidotti (2011; 2013), Elizabeth Grosz (1994) and Claire Colebrook (2014) (for archaeological applications, see Marshall 2000; 2008; 2020). It is no surprise that these thinkers have themselves responded to Spinoza's question both directly and through their engagement with Gilles Deleuze and Félix Guattari (2004). Their feminism combines the power of Spinoza's question with a second critical concept developed from a wider reading of 
Deleuze's philosophy (e.g. 2004) and that of an earlier generation of feminist thinkers like Luce Irigaray (1985): the importance of difference as a productive force in the world (in archaeology, see Bickle 2020; Harris 2021; Marshall 2008).

The reimagining of difference is at the heart of posthumanist feminism (see Cobb \& Crellin, this section). Grosz (2005) notes how difference has tended to be understood in one of two ways over the last century, using examples from traditional feminism. First is comparative difference, where difference between complete entities is measured or represented according to a third term, a metric to determine relations of more or less (Grosz 2005, 5). In seeking to provide women with equal and comparative status to men, egalitarian feminism compares the two given entities of gender against an ideal of what it is to be human. In contrast, 'constitutive difference' or difference by negation, is favoured within feminisms of difference (Grosz 2005, 5). Men and women are no longer understood as separate entities, but terms which require each other, although not reciprocally. Man is rarely defined in relation to woman: it is woman who is defined by not being man, by lacking the characteristics that make man. Significantly, men have characteristics, women are defined by lack thereof (cf. Yates 1993).

In both instances, difference is not a product of the particularity of a single thing, but rather contingent on other bodies in order to provide comparison. This dependence on comparison creates a negative difference: an understanding of a body which relies upon how it measures up to an eternal essence, such as the ideal human, and what it lacks in comparison. In contrast, Grosz (2005) offers us a productive difference, a difference in itself. Here difference identifies how the world comes into existence. Difference is not the comparison of two entities, but rather the shaping and forming of the world, as a potter's hands and the clay they hold work together to differentiate form in the process of making. Differential pressures of force and tension operate through the world producing bodies via this ongoing process of difference in itself: bodies of pots, bodies of people, bodies of thought (cf. Harris 2021, chapter 3).

In addition to difference, a second tool developed from feminist posthumanism is also required: nomadism, which we take from the work of Braidotti (2011). By emphasizing how subjectivity only emerges immanently, within power relations that are unequal and always active, Braidotti's nomadic subject recognizes the power of difference. This embraces the open-ended nature of the body, and positions this explicitly to challenge how dominant narratives are used to impose standardized versions of the human, versions that always have a surprising amount in common with western visions of 'Man'. It is the political commitment that feminism brings that is so essential to our endeavours as archaeologists. Braidotti's nomadism forces us to think through how our narratives have privileged certain kinds of people and certain kinds of relations. The stories we tell too often focus on what Deleuze and Guattari $(2004,323)$ call the majoritarian. Instead, Braidotti (2011) urges us to focus on the minor, on minoritarian approaches, on the possibilities that exist for change and difference. When thinking about bodies, this approach shifts us from looking for fixed and dominant accounts to alternative histories and capacities lodged in the past. It allows us to emphasize how bodies are not one thing; they shift and change, they themselves are nomadic.

These two concepts, difference and nomadism, form critical feminist posthumanist tools to answer the question: what can a body do? These can be positioned alongside the more general posthumanist commitment to opening up the category of human for analysis (Ferrando 2019). Rather than being an ahistorical category, posthumanism emphasizes that humans emerge in specific contexts and in specific assemblages. Critical here is that posthumanism forces us to embrace the non-human. As archaeologists have long recognized, and as we have already mentioned, it is clear that bodies are never just the biological matter of our flesh and blood; their capacities to affect and be affected are shaped by and shape the non-humans that we live alongside. Our bones and muscles, our synapses and neurons, are formed through our engagements with material things (Sofaer 2006). The boundaries here are shifting and blurred. Archaeologically, this is critical: the nonhumans we encounter tell us about the bodies in the past because the non-humans are bodies of the past, bodies that were always more-than-human. What can a body do? If we do not think about the non-human, we cannot answer this question. Difference and nomadic subjectivity situate a feminist posthumanism. Here bodies are never 'less-than' some ideal, but always emergent, forging new relations, gaining new capacities, generating new connections; posing us the question: in a particular time and a particular place, what can a body do?

\section{Bodies in patches}

To explore these ideas in an archaeological context we want to look at two different parts of the world. First, we explore the Chinchorro mummies of coastal 
Peru and Chile; second, an example from the Neolithic of Southern Britain. In taking these two examples, we do not claim any kind of link or necessary connection. However, by bringing them into conversation with one another, a productive-rather than comparative- difference emerges, and with that difference new concepts and ideas. In parallel with the anthropologist Anna Tsing (2015), we treat these two examples as 'patches'. In The Mushroom at the End of the World, Tsing (2015) develops an approach to her evidence that revels in the local, patchy nature of things. In particular she focuses on the strange world of matsutake mushrooms which insert themselves into lives, landscapes, materials and economies of different parts of the world in multiple ways. Rather than trying to 'scale up' to universal explanations or interpretations, Tsing follows the mycelial connections that her mushrooms make; these avoid neat pathways and instead form links that go in complex directions between unexpected elements. Tsing's $(2015,24)$ patches bring together what she terms 'polyphonic assemblages' full of productive difference, just as we seek to do in this paper with our examples.

In our view, patches are rhizomatic assemblages that encourage experimentation and emphasize multi-species interaction. Consequently, they resist the perpetuation of progress narratives and hierarchical relations, instead offering a polyphonic, openended rush of stories. This approach makes room for Braidotti's nomads, Spinoza's immanent bodies and Grosz's productive difference. Here we explore our concepts, in two separate patches, from different places, times and historical periods. The aim is not to understand what our two case-studies are, but rather to explore what two different kinds of bodies can do, in two different contexts, and how we can map these capacities within their local patches from our feminist posthumanist perspective. The two patches offer very different levels of detail, especially about the process of mummification, but such differences can once again be productive rather than limiting.

\section{Chinchorro mummies}

The Chinchorro were small groups of fishers and hunters inhabiting the dry coastal environments of the Atacama Desert in the south-central Andes of Peru and Chile (Arriaza 1995; Sanz et al. 2014). From the sixth millennium $\mathrm{BC}$, they began an elaborate practice of artificial mummification which persisted for more than 4000 years.

Mummification practices varied over time, with a general trend from 'black' to 'red' mummification practices, although these sometimes co-existed.
Both mummification practices entailed a reconstituting of the body: the body was either skinned and disarticulated (black) or eviscerated through incisions across the body (red), before being rearticulated and reinforced with reeds and wood. Black mummies had human features moulded over the form in clay, and patches of animal hide or human skin were then attached and coated in a thin layer of blueblack paint (Arriaza \& Standen 2014, 59-61). The red mummies were stuffed with soils, feathers of seabirds and the skin and hair of camelids. A manganese paste created facial features, the head was adorned with a long wig of human hair, and the final form was painted in bright red ochre (Arriaza \& Standen 2014, 63-4).

Since the discovery of these remains, scholars have endeavoured to explain the origins and motives behind Chinchorro mummification. Their suggestions for mummification range from functional (a way to remove the dead from camp (cf. Arriaza \& Standen 2014, 66) to emotional, with Arriaza (1995) suggesting that mummification displays an act of love and empathy in the face of death. The most common explanation by far, however, is that the Chinchorro participated in the ancestor cult which characterizes many Andean relationships with their dead (Guillén 2004; Lau 2015; Lopez-Hurtado 2015).

Early studies of Chinchorro mummification neglected social and environmental influences to focus on the mummification itself (Santoro et al. 2012, 638). Our posthumanism, however, leads us to connect these bodies to the non-humans that surround them, including the wider environment. Recent research has explored the effects of high levels of arsenic in the drinking water consumed by the Chinchorro peoples (Arriaza et al. 2010; Byrne et al. 2010). Arsenic is a colourless, unscented and tasteless poison, commonly found in the Atacama coastal desert region. Chinchorro communities probably ingested arsenic from contaminated water and marine resources such as aquatic plants and seafood. Today, chronic arsenic poisoning, or arsenosis, is known to cause several health problems from miscarriages, premature birth, neonatal death, stillbirths, neurological disorders and many cancers (Ahmad et al. 2001; HopenhaynRich et al. 2000). In the Camarones valley, natural water sources exhibit arsenic levels 100 times higher than the $10 \mathrm{mg} / \mathrm{L}$ limit recommended by the World Health Organisation (Arriaza et al. 2010, 1274). Consequently, the Chinchorro miscarriage rate was probably 30 times higher than other Andean populations (Arriaza 2005, 255).

Kaulicke's $(2015,117)$ research demonstrates that the more intensive preservation practices are 
applied only to the youngest and even the premature members of the Chinchorro communities. At Camerones 14, the site from where the oldest known Chinchorro mummies are found, infant mortality was 20 to 25 per cent (Moore 2014, 115). The continual stresses of high infant mortality might have affected and altered Chinchorro relationships to death. Arriaza and Standen $(2014,55)$ argue that because Chinchorro society was probably nonstratified, at least not visibly so in the archaeological record, the complex mortuary treatment of children was a way to resolve parental grief rather than a reflection on social position. While this moves the discussion beyond that of ancestor veneration, it risks treating human emotion in an ahistorical manner (cf. Eriksen 2017).

If we think in the minor key, we cannot merely distil this process into a simplistic account of parental grief, or a generalized practice of ancestor veneration. A nomadic narrative attends to the distinctive individualized processes of mummification. The question is not simply why these bodies were preserved in such a way by the living (although this is important), but what do these bodies do? How do these artificially mummified bodies behave differently to the living and to the non-mummified dead? How do the specific compositions of each body behave differently? For example, why were different animal hides chosen for different mummies? These are questions our theoretical approach forces us to ask.

Chinchorro mummies were made using a combination of animal and human. For example, Cam-17 T1:C3's trunk was wrapped in animal hides, probably sea lion, while Chin-1 T1:C3 was wrapped in bird hide, and Chin-1 T1:C1 was wrapped in camelid hide (Arriaza 1995, 6; Aufderheide et al. 1993, 191-3). Adult and child remains were often mixed-neonates and infants were given wigs of human hair, as seen in the red mummy, Morro 1 T25:C5 (Standen 1997, 142), and in one instance a black mummy (Chin $1 \mathrm{T1}: \mathrm{C} 2$ ) had adult fingernails superimposed onto the child's (Aufderheide et al. 1993, 196, 198). To approach these mummies with a focus on the posthuman, and productive difference, we need to consider what kinds of bodies were emerging as they were preserved. The Chinchorro mummified body is differentiated from the slow preservation of the naturally mummified dead in very distinct ways. Its boundaries are unfixed, it is composed as much of vegetal and animal as it is of human, extending our standard conception of the human body, mixing adult and infant elements, and encompassing the environment in which it began. The incorporation of the animal realm and adult hair appears to be the deliberate creation of something different from the living communities who mummified their dead.

Mummified infants may have taken on different affects, capacities to affect and be affected, from the animal and human remains incorporated in their composition, becoming something other-thanhuman (cf. Conneller 2004; Deleuze 1988; Viveiros de Castro 2014). Affects here are alterations of bodily capacities and renegotiations of corporeality. Animal parts wrapped human bodies, offering the possibility of moving differently, entering the sea or the air. The addition of clay enabled mummified forms to be bound and preserved beyond the natural timescale for decay. Perhaps clay could grant a stronger connection with the earth itself, allowing capacities of endurance and resistance to time. Adult fingernails and human hair bridged ages together, creating bodies of multiple times and temporalities. The hands of three-year-old infants were remade with sand cement and adult fingernails (Chin $1 \mathrm{~T} 1: \mathrm{C} 2$ : Arriaza 1995, 6; Aufderheide et al. 1993, 191, 196). They were larger, stronger, and less liable to decay. Affects here work as things that forge productive difference, the process of one body pressing into another, changing what it is a body can do, what a body can feel (Spinoza 2009).

These bodies of multiple capacities, bodies that blur the boundaries of human and non-human, infant and adult, decay and endurance, were bodies that emerged in communities struck by the adverse effects of what we now recognize as arsenic poisoning. Perhaps providing mummies with different affects, adult and animal, human and non-human, gave them, the mummified remains and the bodies that mummified them, an increased capacity to withstand high infant mortality rates. In preventing death from removing infants from the community, by continuing their presence in the group, Chinchorro communities may have been enacting a reconstitution of group vitality.

\section{Neolithic mummies at Wor Barrow}

What happens when we turn to a different patch, in this case Neolithic Britain, and ask what it is that a body can do? The Neolithic is the first period of farming in Britain, which begins around 4100 cal. BC (Ray \& Thomas 2018; Whittle et al. 2011). The period is well known for its monuments, including long barrows, chambered tombs, causewayed enclosures and cursus monuments. Bodies in death were treated in a variety of ways, with fragmentation especially widespread, but cremation, whole burial and more were also employed (Fowler 2010; Smith \& Brickley 2009). These different ways of treating the dead 
acted to create different capacities for the bodies that emerged (Harris 2018; 2021, chapter 5).

Here we focus on one particular site, Wor Barrow, and within that a pair of bodies, one of which was treated differently to others we know of from this period. Wor Barrow is a Neolithic long barrow excavated by Augustus Pitt Rivers between 1893 and 1894 (Allen et al. 2016; Barrett et al. 1991). It consisted of a mortuary structure, later enclosed by a turf mound, and then covered by two further phases of mound; an architectural sequence which probably took place between 3685 and 3540 cal. BC (Allen et al. 2016, 16). Although six bodies were excavated from the main mortuary structure at the centre of the monument, the two we concentrate on here were deposited in the southwest ditch segment: an adult male 25-35 years old in a crouched position, and an infant placed alongside him. The man died many decades before his body was buried in the ditch; depending on which model of the dating evidence you choose, perhaps by 100 years or more (Allen et al. 2016, 14-16). This is a clear example in Neolithic Britain of a body preserved after death that remained articulated, though, in comparison to our South American examples, we can say little about how this was achieved. The man may have died violently, as an arrowhead was found between his ribs. Unfortunately, as the infant was not retained following excavation there is less we can say about this individual, though their role in the story remains critical.

In comparison to the broader treatment of bodies in the Neolithic of Britain, sketched out above, the body of the adult at Wor Barrow was different. At the moment of death, when other bodies began to differentiate themselves from the world of the living, as they rotted and transformed, were buried or burned, his transformation was slowed. He was differentiated away from the world of the dead and retained within the ebb and flow of the living, not as disarticulated bones but as a whole. Neolithic bodies in death could do a great many things. Fragmented bodies could be in more than one place at a time, move around the landscape or be deposited into rivers or pits (Harris 2010; Thomas 1999). Cremated bodies forged intensive memorable events and produced a new material that could again be split up and circulated (cf. Brophy et al. 2018). Whole burials bound memories and relations into singular points in the landscape. Bodies could become parts of monuments. Each of these ways of treating the body drew on the productive differences they made available; they differentiated the body from a singular thing into a multiplicity; they created the potential for new forms of movement, connection, relationships to place and subjectivity to emerge.

For a century or more this body did something different to the others it had once lived alongside, and became something different through that process. Through its preservation the body could do different things; it could operate in society differently; it must have provoked different kinds of memory and recall, relations that operated in the spaces between this body and others it encountered. This body differentiated itself through the forms of encounter it facilitated and the worlds of the past it brought into being. Perhaps elements of this drew on differences in the individual's life: their early childhood may have been spent in a different place to others buried at the monument (Allen et al. 2016, 25).

Yet our emphasis on the minoritarian must force our nomadic gaze away from the body towards the absent infant. Writing stories of those gone is, of course, one of archaeology's strengths. Our reliance solely on the empirical presence of the man's bodypreserved in part because of the patriarchal structures of the nineteenth century not entirely absent from our discipline today-emphasize precisely why we need feminist thought to provoke us consistently to think anew. It also demands that we unashamedly speculate, as speculation can make room for other kinds of stories. We know the preserved male skeleton had been kept among the living for decades, perhaps more than a century. Was it, then, the death of the child that caused his eventual interment? Did the child's body demand that changes were made, that in order for it to do certain things the body of the man had to be buried too? Does the desire for burial, and the power to make demands, lie not in the presence of the highly unusual, mummified, male, but in the more commonplace, but no less affectively powerful, burial of the child? Or did burying the child alongside the preserved body of another help to cover over the memories of the child themselves? Without an emphasis on the nomadic we might miss the difference this makes.

Posthumanism also demands, as we have seen, that we look beyond the human (Braidotti 2013). Two non-humans are immediately and clearly critical. The monument of Wor Barrow itself played a centrifugal role, dragging people and burials into its orbit for centuries after its construction. The relations that endured through the bodies of the dead as they were interred, their capacity to affect and be affected by the living-what they could do-cannot be understood away from their relationships with the non-human body of the barrow. The second nonhuman is more humble but perhaps more deadly: the 
arrowhead found in the ribs of the adult male. The treatment of bodies that experienced violence in Neolithic Britain often includes their burial in monuments (though not after equivalent periods of preservation, it must be said) (Schulting 2012; Schulting \& Wysocki 2005). Here we must engage with the possibility that the intersection of human and non-human bodies in the moment of violence-person firing the arrow, the bow, the arrow, the target-created flows of affect and desire that changed what it was the dead body could do.

\section{Conclusion}

What could a body do? As Spinoza notes, no-one has yet defined the limits of the body's capacities. This is because what a body can do emerges in specific, historically located, assemblages of relations. It emerges in conjunction with humans and non-humans of all sorts. Here we have seen how flows of non-humans such as arsenic helped transform bodies' capabilities, changing their capacities for life, forcing new possibilities in death. We have seen how violence helped create a new possibility for a body in death, before encounters with other bodies, one human and one monumental, changed those capacities again. These different sets of relations reveal bodies that are transformative, open, nomadic, and becoming, but in different ways. They are not versions of standardized Man, but rather historically located, contextual and emergent.

The feminist and posthumanist approach to difference we have sketched here allows for different kinds of human to exist, resisting the strict categorization of people into set types, be that gendered, cultural, or racial. In focusing on the emergent existence of people and things, we are encouraged to see bodies as becomings. They are situated and contextual, and not measured against a transcendent preexisting category. Discussing these specific bodies in this manner may seem parochial. But that is far from the case. Instead, taking this feminist, posthumanist, relational approach is significant not only to our archaeological research, but also to our relationship with the varied bodies that exist today. Like our bodies in the past, this approach demands that we go beyond a milquetoast acknowledgement of diversity. Diversity is given, Grosz (1994) and Deleuze $(2004,280)$ remind us; difference is what gives rise to diversity. In a world where we increasingly appreciate how the bodies of people who do not match the idealized version of Man remain at risk of continuous and horrendous violence, it becomes essential we open archaeology to the possibility of difference, nomadic subjectivities and feminist becomings. We live, right now, in the ruins of global capitalism, and as Tsing (2015) has shown us, the challenge is to learn to live in new ways in those ruins. A first step in this direction, as archaeologists, is to steer away from the certainties and fixities of how we understand the past, and to embrace the immanent question: what can a feminist body do? By seeking answers to this in the past, we can make one small step, from our disciplinary perspective, in making space for difference. As the past remains as central to the present as ever, it is in making space for the nomadic bodies of the past that archaeologists can provide an opening for new kinds of bodies, and new ways of living, in the present.

\section{Acknowledgements}

We would like to thank Hannah Cobb and Rachel Crellin for inviting us to give versions of this paper at the TAG conferences in Syracuse and UCL, and for their comments and those of two very insightful peer reviewers. The research presented here has in part been funded by an AHRC M4C PhD studentship and a Philip Leverhulme Prize (PLP-2016-109).

\section{Note}

1. In the light of the sensitivities involved in the display of human remains, we have chosen not to include any images in this paper.

$$
\begin{array}{r}
\text { Yvonne O'Dell } \\
\text { School of Archaeology and Ancient History } \\
\text { University of Leicester } \\
\text { University Road } \\
\text { Leicester LE1 7RH } \\
\text { UK } \\
\text { Email: yvod2@leicester.ac.uk } \\
\text { Oliver J.T. Harris } \\
\text { School of Archaeology and Ancient History } \\
\text { University of Leicester } \\
\text { University Road } \\
\text { Leicester LE1 7RH } \\
\text { UK } \\
\text { Email: ojth1@leicester.ac.uk }
\end{array}
$$

\section{References}

Ahmad, S.A., M.H.S.U. Sayed, S. Barua, M.H. Khan, M.H. Faruquee \& A. Jalil, 2021. Arsenic in drinking water and pregnancy outcomes. Environmental Health Perspectives 109, 629-31. 
Allen, M.J., M. Smith, M. Jay, J. Montgomery, C.B. Ramsey, G. Cook \& P. Marshall, 2016. Wor Barrow, Cranborne Chase, Dorset: Chronological modelling. London: Historic England.

Arriaza, B., 1995. Beyond Death: The Chinchorro mummies of ancient Chile. London: Smithsonian Institution Press.

Arriaza, B., 2005. Arseniasis as an environmental hypothetical explanation for the origin of the oldest artificial mummification practice in the world. Chungara 37, 255-60.

Arriaza, B., D. Amarasiriwardena, L. Cornejo, V. Standen, S. Byrne, L. Bartkus \& B. Bandak, 2010. Exploring chronic arsenic poisoning in pre-Columbian Chilean mummies. Journal of Archaeological Science 37, 1274-8.

Arriaza, B. \& V. Standen, 2014. Black and red Chinchorro mummies: construction, raw materials and social milieu, in The Chinchorro Culture: A comparative perspective. The archaeology of the earliest human mummification, eds N. Sanz, B. Arriaza \& V. Standen. Arica: UNESCO, 53-70.

Aufderheide, A., I. Muñoz \& B. Arriaza, 1993. Seven Chinchorro mummies and the prehistory of northern Chile. American Journal of Physical Anthropology 91, 189-201.

Barrett, J., R. Bradley \& M. Green, 1991. Landscape, Monuments and Society: The prehistory of Cranborne Chase. Cambridge: Cambridge University Press.

Bickle, P., 2020. Thinking gender differently: new approaches to identity difference in the Central European Neolithic. Cambridge Archaeological Journal 30, 201-18.

Braidotti, R., 2011. Nomadic Subjects: Embodiment and sexual difference in contemporary femininst theory. New York (NY): Columbia University Press.

Braidotti, R., 2013. The Posthuman. London: Polity.

Brophy, K., G. MacGregor \& G. Noble, 2018. Warm air and glowing pyres. Cremating bodies in the Late Neolithic of mainland Scotland, in Neolithic Bodies, eds P. Bickle \& E. Sibbesson. Oxford: Oxbow, 74-91.

Byrne, S., D. Amarasiriwardena, B. Bandak, et al., 2010. Were Chinchorros exposed to arsenic? Arsenic determination in Chinchorro mummies' hair by laser ablation inductively coupled plasma-mass spectrometry (LA-ICP-MS). Microchemical Journal 94, 28-35.

Cipolla, C.N. 2021. Posthuman potentials: considering collaborative Indigenous archaeology. Cambridge Archaeological Journal 31, 509-14.

Colebrook, C., 2014. Sex After Life: Essays on extinction, Vol 2. Ann Arbor (MI): Open Humanities Press.

Conneller, C. 2004. Becoming deer: corporeal transformations at Star Carr. Archaeological Dialogues 11, 37-56.

Crellin, R.J. \& O.J.T. Harris, 2021. What difference does posthumanism make? Cambridge Archaeological Journal 31, 469-75.

Crellin, R.J., C.N. Cipolla, L.M. Montgomery, O.J.T. Harris \& S.V. Moore, 2021. Archaeological Theory in Dialogue: Situating relationality, ontology, posthumanism and Indigenous paradigms. London: Routledge.

Deleuze, G., 1988. Spinoza: Practical philosophy. San Francisco (CA): City Lights Books.
Deleuze, G., 2004. Difference and Repetition. London: Bloomsbury.

Deleuze, G., 2006. Nietzsche and Philosophy. New York (NY): Columbia University Press.

Deleuze, G. \& F. Guattari, 2004. A Thousand Plateaus: Capitalism and schizophrenia, London: Continuum.

Edgeworth, M., 2012. Follow the cut, follow the rhythm, follow the material. Norwegian Archaeological Review 45, 76-92.

Eriksen, M.H., 2017. Don't all mothers love their children? Deposited infants as animate objects in the Scandinavian Iron Age. World Archaeology 49, 338-56.

Ferrando, F., 2019. Posthumanist Philosophy. London: Bloomsbury.

Fowler, C., 2010. Pattern and diversity in the Early Neolithic mortuary practice of Britain and Ireland: contextualising the treatment of the dead. Documenta Praehistorica 37, 1-22.

Fredengren, C., 2013. Posthumanism, the transcorporeal and biomolecular archaeology. Current Swedish Archaeology 21, 53-71.

Fredengren, C., 2018. Archaeological posthumanities: feminist re-invention of science and material pasts, in A Feminist Companion to the Posthumanities, eds C. Åsberg \& R. Braidotti. New York (NY): Springer, 129-40.

Grosz, E.A., 1994. Volatile Bodies: Toward a corporeal feminism. Bloomington (IN): Indiana University Press.

Grosz, E.A., 2005. Bergson, Deleuze, and the becoming of unbecoming. Parallax 11, 4-13.

Guillén, S., 2004. Artificial mummies from the Andes. Collegium Antropologicium 28, 141-57.

Harris, O.J.T., 2010. Emotional and mnemonic geographies at Hambledon Hill: texturing Neolithic places with bodies and bones. Cambridge Archaeological Journal 20, 357-71.

Harris, O.J.T., 2018. Both permeable and partible: exploring the body world of Early Neolithic southern Britain, in Neolithic Bodies, eds P. Bickle \& E. Sibbesson. Oxford: Oxbow, 7-24.

Harris, O.J.T., 2021. Assembling Past Worlds: Materials, bodies and architecture in Neolithic Britain. London: Routledge.

Hopenhayn-Rich, C., S.R. Browning, I. Hertz-Picciotto, C. Ferreccio, C. Peralta \& H. Gibb, 2000. Chronic arsenic exposure and risk of infant mortality in two areas of Chile. Environmental Health Perspectives 108, 667-73.

Irigaray, L., 1985. This Sex Which Is Not One. Ithaca (NY): Cornell University Press.

Kaulicke, P., 2015. Corporealities of death in the Central Andes (ca 9000-2000 BC), in Death Rituals, Social Order, and the Archaeology of Immortality in the Ancient World: 'Death shall have no dominion', eds C. Renfrew, M. Boyd \& I. Morley. New York (NY): Cambridge University Press, 111-29.

Lau, G., 2015. Different kinds of dead: presencing Andean expired beings, in Death Rituals, Social Order, and the Archaeology of Immortality in the Ancient World: 'Death shall have no dominion', eds C. Renfrew, M. Boyd \& 
I. Morley. New York (NY): Cambridge University Press, 168-86.

Lopez-Hurtado, E., 2015. Far away, so close: living with the ancestors in Panquilma, Peruvian central coast, in Funerary Practices and Models in the Ancient Andes: The return of the living dead, eds P. Eeckhout \& L. S. Owens. New York (NY): Cambridge University Press, 24-33.

Marshall, Y., 2000. Reading images stone B.C. World Archaeology 32, 222-35.

Marshall, Y., 2008. Archaeological possibilities for feminist theories of transition and transformation. Feminist Theory 9, 25-45.

Marshall, Y., 2020. Taking indigenous theory seriously: Whakapapa and chevron pendants, in Theory in the Pacific, The Pacific in Theory, ed. T. Thomas. London: Routledge, 299-328.

Marshall, Y., 2021. Indigenous theory is theory: Whakapapa for archaeologists. Cambridge Archaeological Journal 31, 515-24.

Marshall, Y. \& B. Alberti, 2014. A matter of difference: Karen Barad, ontology and archaeological bodies. Cambridge Archaeological Journal 24, 19-36.

Meskell, L. \& R. Joyce, 2003. Embodied Lives: Fguring ancient Maya and Egyptian experience. London: Routledge.

Moore, J., 2014. A Prehistory of South America: Ancient cultural diversity on the least known continent. Boulder (CO): University Press of Colorado.

Ray, K. \& J. Thomas, 2018. Neolithic Britain: The transformation of social worlds. Oxford: Oxford University Press.

Robb, J.E. \& O.J.T. Harris, 2013. The Body in History: Europe from the Palaeolithic to the future. Cambridge: Cambridge University Press.

Santoro, C., M. Rivadeneira, C. Latorre, F. Rothhammer \& V. Standen, 2012. Rise and decline of Chinchorro sacred landscapes along the hyperarid coast of the Atacama Desert. Revista de Antropología Chilena 44, 637-53.

Sanz, N., B. Arriaza \& V. Standen (eds), 2014. The Chinchorro Culture: A comparative perspective. The archaeology of the earliest human mummification. Arica: UNESCO.

Schulting, R., 2012. Skeletal evidence for interpersonal violence beyond mortuary monuments in southern Britain, in Sticks, Stones and Broken Bones: Neolithic violence in a European perspective, eds R. Schulting \& L. Fibiger. Oxford: Oxford University Press, 223-48.

Schulting, R. \& M. Wysocki, 2005. 'In this Chambered Tumulus were found Cleft Skulls ...': an assessment of the evidence for cranial trauma in the British
Neolithic. Proceedings of the Prehistoric Society 71, 107-38.

Smith, M. \& M. Brickley, 2009. People of the Long Barrows: Life, death and burial in the earlier Neolithic. Stroud: History Press.

Sofaer, J., 2006. The Body as Material Culture: A theoretical osteoarchaeology. Cambridge: Cambridge University Press.

Spinoza, B., 2009. The Ethics (Ethica Ordine Geometrico Demonstrata). Project Gutenberg. https://www. gutenberg.org/files/3800/3800-h/3800-h.htm (accessed 14 December 2020).

Standen, V., 1997. Temprana complejidad funeraria de la Cultura Chinchorro (norte de Chile) [Early funerary complexity of the Chinchorro Culture (northern Chile]. Latin American Antiquity 8, 134-56.

Thomas, J., 1999. Understanding the Neolithic. London: Routledge.

Tilley, C., 1994. A Phenomenology of Landscape: Places, paths and monuments. Oxford: Berg.

Treherne, P., 1995. The warrior's beauty: the masculine body and self-identity in Bronze Age Europe. Journal of European Archaeology 3, 105-44.

Tsing, A.L., 2015. The Mushroom at the End of the World: On the possibility of life in capitalist ruins. Princeton (NJ): Princeton University Press.

Viveiros de Castro, E., 2014. Cannibal Metaphysics. Minneapolis (MN): University of Minnesota Press.

Whittle, A., F. Healy \& A. Bayliss, 2011. Gathering Time: Dating the early Neolithic enclosures of southern Britain and Ireland. Oxford: Oxbow.

Yates, T., 1993. Frameworks for an archaeology of the body, in Interpretative Archaeology, ed. C. Tilley. London: Berg, 31-72.

\section{Author biographies}

Yvonne O'Dell is an AHRC M4C PhD Student at the University of Leicester. Her research focuses on affect, Spinoza and posthumanism set in the context of the preColonial, Colonial and post-Colonial Americas.

Oliver J.T. Harris is Associate Professor of Archaeology at the University of Leicester. He is the co-author of The Body in History, Archaeological Theory in the New Millennium and Archaeological Theory in Dialogue and the sole author of Assembling Past Worlds. His research mostly focuses on archaeological theory and Neolithic and Bronze Age Europe. 